\title{
La traducción de terminología judicial: análisis pragmático- funcional del personal que colabora con la Administración de Justicia en Francia y en España
}

\author{
The translation of judicial terminology: A pragmatic- \\ functional analysis of justice administration personnel in \\ France and Spain
}

\author{
CARMEN EXPÓSITO CASTRO \\ Ir1excac@uco.es \\ Universidad de Córdoba
}

Fecha de recepción: 19 de julio de 2018

Fecha de aceptación: 15 de octubre de 2018

Resumen: Los actos procesales procedentes de los órganos jurisdiccionales son objeto de encargo frecuente entre los traductores e intérpretes jurados y judiciales. Algunos de los conceptos que aparecen en los textos de ámbito judicial hacen referencia a la denominación y funciones del personal que participa en la constitución, desarrollo y resolución del proceso judicial. Es esencial que estos conceptos, a los que se refieren los términos judiciales, se traduzcan de forma correcta y coherente para no crear confusión y garantizar que los traductores, intérpretes y los propios juristas, destinatarios de la traducción o interpretación, los comprendan. Sin embargo, debido a las diferencias entre los ordenamientos judiciales español y francés, estos términos a menudo carecen de equivalencias exactas. Con el fin de mejorar la competencia temática en materia de traducción jurídica y judicial, los objetivos de este artículo son dos: realizar un análisis pragmático-funcional de estos términos en relación con las funciones de este personal judicial y proponer posibles técnicas de traducción y soluciones para traducir estos términos al español. Para ello, elaboramos previamente un corpus monolingüe de decisiones judiciales en francés correspondiente a encargos reales de traducción del que se extrajo una lista de términos más frecuentes relacionados con el personal judicial con la ayuda del programa AntConc. Por último, tras un minucioso proceso de documentación a partir de fuentes lexicográficas jurídicas francesas, en este trabajo presentamos un glosario francés-español de términos correspondientes al personal judicial.

Hemos podido demostrar que debido a que las funciones difieren en cada uno de los ordenamientos jurídicos, resulta muy difícil traducir estos 
referentes legales-culturales franceses al español sin la competencia temática adecuada.

Palabras clave: actos procesales, traducción judicial, personal judicial, referentes culturales jurídicos,

Abstract: Procedural acts emanating from judicial bodies are a frequent commission among sworn and judicial translators and interpreters. Some of the concepts that appear in these judicial texts are related to the designations and functions of the personnel involved in the constitution, development and resolution of the judicial process. It is essential that these concepts, which are referred to by judicial terms, are translated correctly and consistently so as not to give rise to confusion and ensure that they are fully understood by translators, interpreters and the jurists themselves, who are the recipients of the translation or interpretation. However, due to the differences in the Spanish and French judicial systems, these terms often lack exact equivalences. With a view to improving thematic competence in legal and judicial translation, the objectives of this article are twofold: to carry out a pragmatic-functional analysis of these terms in context in relation to the functions of this judicial personnel and propose possible translation techniques and solutions to translate these terms into Spanish. For this purpose, we previously compiled a monolingual corpus of judicial decisions in French corresponding to real translation commissions from which a list of the most frequent terms related to judicial personnel was extracted with the aid of the AntConc program. Finally, following a thorough process of documentation using French legal lexicographical sources, in this paper we present a FrenchSpanish glossary of terms corresponding to judicial personnel. We show that because the functions differ in each legal system, it is a very complex task to translate these French legal-cultural referents into Spanish without the proper thematic competence.

Keywords: procedural acts, judicial translation, judicial personnel, legalcultural referents

\section{INTRODUCCIÓN}

La traducción y la interpretación dentro del amplio campo del Derecho incluyen la traducción e interpretación judicial, que se refiere exclusivamente a los actos en los que intervienen los órganos de la administración de justicia. En el ámbito de la traducción jurídica, la competencia temática es imprescindible, que se refiere en gran medida al perfecto conocimiento de los 
órganos jurisdiccionales, su composición y funcionamiento. En esos órganos trabajan y colaboran una serie de personas, funcionarias o no, que imparten justicia y auxilian la labor judicial. En esta investigación, vamos a centrarnos en ese aspecto concreto, el personal que colabora con la Administración de justicia, y específicamente el personal que forma parte del ordre judiciaire francés, el más amplio de los dos órdenes jurisdiccionales franceses. Nuestros objetivos son: realizar un análisis pragmático-funcional de los términos relacionados con las funciones del personal judicial y proponer posibles técnicas de traducción para traducir estos términos al español mejorando así la competencia temática y traductora por parte de toda la comunidad académica y profesional de la traducción e interpretación jurídica y judicial.

Este trabajo procede de una investigación terminológica anterior a partir de un corpus de veinticinco resoluciones judiciales francesas del ordre judiciaire francés, encargos reales de traducción al español. Todos esos textos se introdujeron en el programa de concordancias y frecuencias AntConc para obtener un listado terminológico judicial del que se seleccionaron 110 términos judiciales. La documentación e investigación de los términos seleccionados se ha llevado a cabo desde un punto de vista pragmático y funcional en el ámbito de la traducción judicial. El resultado fue un conjunto de fichas término-traductológicas bilingües en las que la propuesta del término en español se basaba en la contextualización del término en francés.

El análisis se enmarcó en un ordenamiento jurídico concreto de partida y otro específico de llegada; ya que consideramos que, en traducción jurídica y judicial, la investigación terminológica, a diferencia de otros ámbitos, como puede ser el científico-técnico, debe efectuarse exclusivamente entre dos países y dos ordenamientos específicos. En nuestro caso, nos limitamos a Francia y España.

En el presente artículo exponemos en primer lugar, la información relativa al personal que trabaja para y con la justicia en Francia y en España, aspecto que enriquece la competencia temática; a continuación, proponemos las técnicas de traducción que se pueden emplear, basándonos en propuestas de autores anteriores como Holl (2012) y Orozco (2014). Finalmente, presentamos un glosario bilingüe correspondiente a los términos del personal judicial, resultado de nuestra investigación previa.

Consideramos que nuestra aportación será útil para la enseñanzaaprendizaje de la traducción e interpretación jurídica, jurada y judicial 
francés<>español y para los profesionales de este ámbito, sobre todo con vistas a mejorar su competencia temática.

\section{Personal de la Administración de Justicia en Francia}

El primer concepto que debe ser aclarado es el de magistrature, que en Francia engloba a dos tipos de profesionales. Esta denominación se refiere a dos grupos diferenciados de magistrats, los magistrats du siège y los magistrats du parquet. Los primeros, en términos generales, corresponden a los juges y los segundos son los que se conocen en general como procureurs.

En la página del Ministerio de Justicia francés, la información relativa al personal al servicio de la justicia aparece clasificada por colectivos profesionales. Las dos primeras categorías nos van a permitir aclarar ese concepto de magistrat en francés con objeto de poder nombrarlo en español. Exponemos previamente las funciones del personal en ambos países y a continuación aportaremos nuestro glosario bilingüe.

\subsection{Magistrats du siège}

Los magistrats du siège, o magistrature assise, reciben este nombre en francés por estar sentados, son los juges cuya equivalencia en español corresponde a la de juez. Al igual que ocurre en derecho español, los jueces son los encargados de velar por el correcto desarrollo del proceso y son quienes dictan las resoluciones judiciales conforme a Derecho.

Es necesario aclarar que en Francia existen numerosos tipos de jueces en función del tribunal en el que desarrollan su labor, de la materia en la que son competentes 0 de la fase del procedimiento en la que intervienen. La importancia de quien examina un asunto y dicta una resolución recae en Francia sobre los jueces a diferencia de España, donde tal labor se refiere a los juzgados y tribunales en los que los jueces llevan a cabo su función, en muchos casos sin una especialización concreta en la materia. Esta diferencia, en la práctica, se refleja en el hecho de que en Francia encontramos en las mismas dependencias de un tribunal, a jueces especializados en distintas materias tanto civiles como penales.

Teniendo en cuenta que los juzgados en España son órganos unipersonales, algunas de las funciones de los jueces especializados franceses son equivalentes a las funciones de algunos juzgados españoles. 


\subsubsection{Juge d'instance}

Este juez trabaja en un tribunal d'instance francés, preside las audiencias y toma su decisión solo, asistido por un greffier, cargo que se verá más adelante. Tiene competencia en litigios, especialmente entre particulares, relativos a los créditos de consumo, arrendamientos urbanos, tutela de asuntos civiles, protección de mayores... de una cuantía inferior a 10000 euros. Resuelve en primera instancia, aunque queda abierta la vía del appel (apelación). Desde el 1 de enero de 2017, con la desaparición de las juridictions de proximité, los tribunaux d'instance franceses han asumido las funciones que desempeñaban esos órganos.

El juge d'instance ejerce también las funciones de juge des tutelles (juez de tutela). Este juez del tribunal d'instance está especializado en la vigilancia de las administraciones legales y de tutelas relativas a las personas mayores de edad. La tutela es el procedimiento que se pone en marcha cuando una persona no posee la capacidad de ocuparse sola de sí misma diariamente. Este juez tiene una misión triple: está encargado de vigilar la gestión de las cuentas de la persona protegida, interviene para autorizar algunos actos especialmente importantes de las personas protegidas y tiene un poder propio de decisión, por ejemplo, para nombrar a un tutor ad hoc cuando existe una contradicción de intereses entre un menor y su representante legal.

\subsubsection{Juge aux affaires familiales}

El juge aux affaires familiales, habitualmente llamado JAF, tiene competencia en asuntos relativos a la familia. Sus funciones en este ámbito, se centran en los procedimientos de divorcio y separación de cuerpos, en la determinación de los titulares de la patria potestad y las condiciones de su ejercicio, en la tutela de menores, así como la atribución de nombres, cambios de nombre, fijación y revisión de las obligaciones alimentarias, de mantenimiento y educación de los hijos, contribución a los gastos del matrimonio o pareja de hecho y la protección de las víctimas de violencia de género.

\subsubsection{Juge de l'exécution}

Este magistrado francés, llamado por lo general JEX, resuelve las dificultades ocasionadas durante la ejecución de una resolución judicial en materia civil. Por ejemplo, es competente en materia de procedimiento de expulsión y embargo (reclamación de la forma del embargo, de los bienes embargables, del importe de los intereses en caso de error...). Este juez solamente puede actuar si existe un título ejecutivo que haga constar un 
crédito o que ordene una expulsión y en caso de que haya un procedimiento de ejecución en curso. Sus decisiones pueden apelarse dentro de los quince días siguientes a su notificación.

\subsubsection{Juge des libertés et de la détention}

El juge des libertés et de la détention (JLD) es uno de los jueces que interviene cuando están en juego los derechos de las personas. Este juez determina simplemente si procede acceder a las medidas cautelares, especialmente la prisión provisional (Peñaranda, 2015: 23), pero tiene otras competencias relativas a la puesta en libertad de los ciudadanos o la prolongación de la prisión preventiva; está asistido por un greffier. Desde el 1 de septiembre de 2017, su función, al igual que la de otros jueces, se ha especializado. Este juez interviene en otros ámbitos distintos al penal, cuando se trata de una libertad individual.

\subsubsection{Juge d'instruction}

En el procedimiento penal francés, este profesional es el encargado de reunir el conjunto de los elementos de un delito para permitir el posible enjuiciamiento de su autor. Interviene obligatoriamente cuando se ha cometido un delito y a menudo en los delitos leves y complejos. Cumple las mismas funciones que el Juez de Instrucción español. Una vez que termina su trabajo, el juge d'instruction puede dictar un auto de sobreseimiento o enviar a la persona investigada ante la cour d'assises o el tribunal correctionnel para ser juzgada. Sus autos son susceptibles de recurso.

\subsubsection{Juge de l'application des peines (JAP)}

Según el artículo 712-1 del Code de procédure pénale francés, este juez está encargado de fijar las principales modalidades de la ejecución de las penas privativas o restrictivas de libertad, orientando y controlando las condiciones de su aplicación. Es similar a la función del Juez de Vigilancia Penitenciaria en España.

\subsubsection{Juge de la mise en état}

El juge de la mise en état es un juez del tribunal de grande instance encargado de velar por el correcto desarrollo del proceso civil. De acuerdo con Campos Plaza (2010: 80), un caso solo será juzgado si está en état, es decir si el expediente está completo y los adversarios se han comunicado mutuamente sus argumentos y sus pruebas. Este juez se nombra para vigilar la instrucción de un proceso civil complejo. 


\subsubsection{Juge des enfants}

El juge des enfants está especializado en los problemas de la infancia y la adolescencia. En materia civil, es competente en asistencia educativa, protección judicial de menores emancipados y de la medida judicial de ayuda a la gestión del presupuesto familiar. Tiene, por tanto, una función doble: protege a los menores en situación de peligro y juzga a los menores delincuentes; en unos casos actúa como juez único y en otros casos preside el tribunal pour enfants asistido por dos jueces legos. En Francia, este magistrado es competente tanto en temas de orden civil como penal, a diferencia del juez de menores español que, únicamente, tiene competencia en procedimientos penales de menores.

De estos ocho magistrats du siège franceses, únicamente el primero de los que hemos presentado, forma parte del tribunal d'instance; todos los demás jueces se ubican en el tribunal de grande instance, el órgano central de la primera instancia en Francia.

\subsection{Magistrats du parquet}

Dentro de la denominación magistrats du parquet, también llamado ministère public, se encuentra la función principal de procureur. Los magistrats du parquet, a diferencia de los anteriores, intervienen de pie. Esta denominación, como indica Cornu (2016: 738), deriva del sustantivo «parc, propr. petit enclos, d'où : partie d'une salle de justice où se tiennent les juges (ainsi nommée à cause de la barre)». El conjunto de estos profesionales en Francia también recibe el nombre de magistrature debout puesto que realizan sus alegatos de pie, de ahí su nombre. Estos profesionales pertenecen al Ministère public francés (también denominado Parquet) que de acuerdo con Delgado Pugés (2010: 122-123):

$$
\begin{aligned}
& \text { [...] es un órgano con rango de autoridad [...] que ejerce la acción } \\
& \text { pública contra las infracciones que hayan causado algún problema } \\
& \text { de orden público, y que vela por los intereses más generales de la } \\
& \text { población ante todas las jurisdicciones del ordenamiento judicial. Se } \\
& \text { encarga de emprender acciones penales y tiene el cometido de } \\
& \text { acusar (o no acusar). En Francia, está bajo la jerarquía del poder } \\
& \text { político a través del Ministro de Justicia (Garde des Sceaux) y la } \\
& \text { Dirección de Asuntos Penales e Indultos. }
\end{aligned}
$$

Son los profesionales que representan la acusación pública del Ministerio Fiscal francés. En Francia, se diferencian tres categorías: los procureurs, los avocats généraux y los substituts. En lo que se refiere a estas funciones del Ministerio Fiscal en Francia, nos remitimos al trabajo de Soriano Barabino (2013: 54) quien expone que: 


\begin{abstract}
Dentro de los procureurs cabe diferenciar entre el Procureur de la République, cabeza del Ministerio Público en el tribunal de grande instance, y el Procureur General, cabeza del Ministerio Público en la cour d'appel o en la Cour de cassation. Junto a los procureurs son también magistrats du parquet los avocats généraux que, lejos de ser abogados como podría incitarnos a pensar su nombre, no son sino los representantes del Ministerio público en las Cours de Cassation, cours d'appel y cours d'assises. Finalmente, los substituts son también representantes del Ministerio público a los que el Procureur de la République delega una serie de competencias principalmente en el ámbito penal.
\end{abstract}

Basándonos en el hecho de que esas categorías corresponden a funciones dentro del Ministerio Fiscal, el concepto general equivalente al de procureur es el de fiscal en España, y podemos afirmar que recibe distintos nombres en función de la jerarquía del órgano en el que actúe dicho profesional. Este magistrat en Francia representa al Ministerio Público ante todos los órganos jurisdiccionales del orden judicial francés. Según el principio de indivisibilidad de la Fiscalía, cada uno de sus miembros puede sustituir a otro en cualquier fase del procedimiento. Cuando se ha cometido una infracción, el procureur de la République puede perseguir a su autor ante un tribunal o una cour d'assises; interviene tras haber sido informado por los servicios policiales, de gendarmería o por los servicios del Estado, así como si hay una denuncia por parte de un particular. Se inicia en ese caso la acción pública.

El procureur de la République es el representante del Ministerio Público y jefe del Parquet (Fiscalía) ante el tribunal de grande instance. Por otro lado, el procureur général es igualmente representante del Ministerio Público y jefe del Parquet ante la Cour de cassation, la Cour des comptes y las cours d'appel.

Con objeto de entender mejor la jerarquía del Ministerio Fiscal francés, presentamos una tabla de las distintas categorías de procureurs en Francia en función del órgano en el que intervienen:

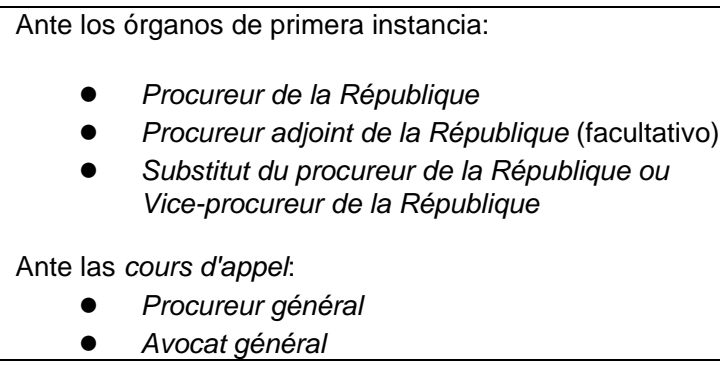

Hikma 17 (2018), 33 - 54 


\begin{tabular}{|l|}
\hline - Substitut général \\
Ante la Cour de cassation: \\
- Procureur général \\
- Premier avocat général \\
- Avocat général \\
\hline
\end{tabular}

Tabla 1: Clasificación en Francia por órganos jurisdiccionales Fuente: Página internet del Ministerio de Justicia francés

En ese listado puede observarse el orden jerárquico de los fiscales; los avocats généraux son fiscales auxiliares del procureur géneral en las cours d'appel y la Cour de cassation. A pesar de su denominación, en la que se incluye el sustantivo avocat, no debe confundirse su función con la de los avocats. Por otro lado, los substituts asisten al procureur de la République (substitut du procureur de la République) en un órgano de primera instancia o al procureur général (substitut général) en una cour d'appel. Del mismo modo que la aclaración anterior relativa a avocat, el término procureur no debe provocar el falso amigo «procurador» que corresponde a una función totalmente diferente en España, como veremos más adelante.

Los procureurs généraux se nombran en Consejo de Ministros y los procureurs de la République se nombran mediante decreto del Presidente de la República previo dictamen simple del Conseil supérieur de la magistrature. Es interesante destacar que, a lo largo de su carrera, los procureurs y los juges en Francia pueden trabajar indistintamente en una u otra función.

\subsection{El greffier en chef $y$ el greffier}

El Director del servicio de la secretaría judicial, greffier en chef, lleva a cabo funciones jurídicas, de gestión y supervisión en los tribunales del orden judicial. Tiene que hacer frente a tareas muy diversas como jefe de la secretaría y supervisa el trabajo de los greffiers y funcionarios de la Administración de justicia. También participa en el desarrollo de presupuestos, garantiza la aplicación y asegura la correcta gestión de los recursos materiales. Colabora igualmente, con los jefes de los tribunales y pone en práctica sus decisiones. Este profesional interviene en múltiples ámbitos.

Por su parte, el greffier, jerárquicamente inferior al greffier en chef, es una figura esencial para el buen funcionamiento del servicio público de la justicia, asiste a los magistrats y autentica actos judiciales. Su actuación es fundamental en el funcionamiento de la justicia, registra los casos, informa a las partes de las fechas de las audiencias y de cierre, prepara los expedientes para los jueces, toma nota del desarrollo de los juicios orales, levanta las 
actas, etc. Cualquier acto realizado en su ausencia puede ser anulado. El greffier también desempeña un papel de intermediario entre abogados, el público y los jueces y fiscales. Asimismo, informa, orienta y ayuda a los usuarios en el cumplimiento de los trámites o procedimientos judiciales.

\title{
2.4. Profesiones liberales al servicio de la justicia en Francia
}

\subsubsection{Avocats}

La profesión de avocat es una profesión autónoma e independiente cuya labor es defender y representar los intereses de las partes ante la justicia. Según la Loi 90-1259, du 31 décembre 1990 portant réforme de certains professions judiciaires et juridiques, y de acuerdo con la investigación de Mallandrich Miret (2013) sobre este profesional en Francia:

\begin{abstract}
[...] los abogados ejercen tres funciones principales. Como en España, se les encomienda la función de asesoramiento jurídico con carácter general, así como la asistencia técnica de las partes en juicio. Esta última función la ostentan con carácter exclusivo, siendo los únicos que pueden intervenir en la defensa de los intereses de las partes en un proceso judicial, siempre que éstas no decidan defenderse por sí mismas. A diferencia del ordenamiento jurídico español, en el que la función de representación de las partes la ejercen los procuradores, en Francia, los abogados también ejercen la función de representar a las partes en todos los procesos en los que intervengan.
\end{abstract}

Asimismo, informan a sus clientes acerca de sus derechos y obligaciones, así como de las vías de procedimiento existentes para la resolución del litigio. La asistencia de un abogado no es siempre obligatoria, depende tanto del asunto en cuestión como del órgano jurisdiccional competente. El avocat en Francia puede compararse por su actividad y funciones al abogado en España.

Cabe destacar en este grupo la desaparición de la figura de los avoués, antiguos juristas que representaban a las partes en las cours d'appel, y cuya intervención era obligatoria. Este profesional podía compararse en algunas de sus funciones al procurador en España. En nuestro contexto de terminología y traducción es relevante conocer un término que ya no existe porque en documentos redactados en una fecha anterior, seguirá apareciendo y habrá que aportar una solución. La figura desapareció el 1 de enero de 2012, en virtud de la Loi no 2011-94 du 25 janvier 2011 portant réforme de la représentation devant les cours d'appel que presentaba cuatro bloques: la integración de la profesión de avoué a la de avocat y sus 
consecuencias, la indemnización de los avoués y sus trabajadores, las ayudas a su reconversión y las modalidades de financiación de la reforma ${ }^{1}$.

\subsubsection{Los avocats auprès du Conseil d'État et de la Cour de cassation}

Eran llamados anteriormente avocats aux Conseils, son abogados que tienen el monopolio de la representación de los justiciables en las dos altas jurisdicciones francesas, la Cour de cassation y el Conseil d'État. Siguen una formación específica para ejercer esta profesión. Tal y como expone Soriano Barabino (2013: 55), en estos tribunales, en los que no se juzga ya sobre el fondo sino que se casan (o no) decisiones tomadas por tribunales inferiores, el papel de los avocats aux conseils consiste en presentar observaciones escritas sobre el procedimiento y en argumentar acerca de cuestiones de derecho. Esta categoría de abogados en Francia pertenece a la figura de officier ministériel, concepto que veremos más adelante. Los nombra el Ministro de Justicia.

No existe esta categoría de abogados en España. Quizá esta denominación puede hacer pensar en la de abogado del Estado, pero este profesional en España cumple otro tipo de función, aun siendo abogados.

\subsubsection{Los huissiers de justice}

La página del Ministerio de Justicia francés define al huissier de justice de la siguiente manera: «[il] est tout à la fois un professionnel libéral, un juriste performant, un officier ministériel et un officier public». Mallandrich Miret (2013) explica que el estatuto personal del huissier de justice «se encuentra regulado en el ordenamiento jurídico francés, en la Ordonnance no 45-2592 de 20 de noviembre de 1945 que a su vez fue desarrollada por el Décret no 56-222 de 29 de febrero de 1956, así como en otras normas sectoriales». Tal y como aclara la autora, este profesional tiene la categoría de officier ministériel:

Esta calidad de "officier ministériel" implica que se trata de una profesión ejercida bajo reglamentación y autorización de Gobierno, otorgándoles el ejercicio de determinadas funciones con carácter exclusivo. No se trata de un funcionario sino de un profesional liberal cuyos honorarios están sujetos a arancel.

Asimismo, se trata de un profesional que tiene como característica que puede dar fe pública en algunos supuestos determinados por (sic) legalmente. En ese sentido se trata de un "officier public". [...]

${ }^{1}$ Información extraída del Rapport d'information n 580 du Sénat du 4 juin 2014 fait au nom de la commission des lois constitutionnelles, de législation, du suffrage universel, du Règlement et d'administration générale sur la mise en oeuvre de la loi réformant la procédure d'appel. Disponible en: https://bit.ly/2BaD0Z6 [Fecha de consulta: 10 de junio de 2018].

Hikma 17 (2018),33 - 54 
Se trata de un cargo de titularidad estatal que ejercen dentro de una delimitación territorial determinada que se corresponde al Tribunal de Gran Instance al que están asignados. [...] Las funciones del Huissier de Justice están delimitadas en el art. 1 de l'ordonnance 45-2592.

Este profesional de la justicia francesa ya ha sido equiparado con los conceptos en español de ujier u oficial de juzgado (Campos Plaza, 2010) así como agente judicial, pero estas funciones en España son mucho menos especializadas que la de huissier en Francia. En alguna de sus funciones y características esta función podría compararse con algunas correspondientes a los notarios en España. Sin embargo, de la explicación anterior podemos deducir que esas funciones en España no las desempeña ningún profesional independiente con cargo de titularidad estatal, sino que las lleva a cabo un funcionario. En el apartado 2.4. se ampliará información sobre las funciones semejantes al huissier de justice francés.

\section{Personal de la Administración de JuSticia en España}

Con objeto de mostrar una presentación por grupos de profesionales del mismo modo que se ha presentado para Francia, nos basamos en la organización por colectivos y profesionales que recoge el Portal de la Administración de Justicia del Ministerio de Justicia español.

\subsection{Jueces y magistrados}

Esta categoría de personal corresponde a lo que Soriano Barabino (2013: 51) denomina personal juzgador. La diferencia entre los términos juez y magistrado obedece, por un lado, a la categoría que ostentan por su experiencia profesional y por otro lado, al hecho de «que el órgano impartidor de justicia sea unipersonal o colegiado» (Peñaranda, 2011: 17). Los jueces ejercen sus funciones en juzgados que no son de capital de provincia o de poblaciones importantes, representan la categoría menor de la carrera judicial dentro de las tres que enuncia el artículo 299 de la Ley Orgánica del Poder Judicial: Magistrado del Tribunal Supremo, Magistrado y Juez. En lo que se refiere a los Magistrados, todos están adscritos a Tribunales, es decir, a órganos judiciales colegiados, sea cual sea su jerarquía y su función (ídem).

Este primer grupo en España corresponde al de los magistrats du siège en Francia, y el siguiente, que presentamos a continuación, sería equivalente al colectivo francés de los magistrats du parquet. Cabe incidir en el doble referente del término magistrat que no puede ser únicamente interpretado en español como «magistrado», puesto que una parte de su significado en 
francés coincide con esa traducción en español, pero el término también se refiere a la equivalencia funcional de fiscal. Por consiguiente, la traducción de magistrat en español dependerá siempre del contexto.

\subsection{Fiscales}

El colectivo de fiscales se considera un cuerpo de funcionarios aparte del de los jueces y magistrados, pertenecen al Ministerio Fiscal, que tal y como enuncia el artículo 124 de la Constitución:

Tiene por misión promover la acción de la justicia en defensa de la legalidad, de los derechos de los ciudadanos y del interés público tutelado por la ley, de oficio o a petición de los interesados, así como velar por la independencia de los tribunales y procurar ante estos la satisfacción del interés social.

El Fiscal es la autoridad pública encargada del ejercicio de la acción de la justicia en los procesos penales, interviniendo así mismo en otro tipo de procedimientos judiciales en defensa de la legalidad y del interés público. De acuerdo con Delgado Pugés (2010: 120), el Estatuto Orgánico del Ministerio Fiscal (Ley 50/81 de 30 de diciembre modificada por la Ley 14/2003 de 26 de mayo) regula la normativa de esa institución y «contiene la regulación básica de las funciones, la estructura y organización, normas de funcionamiento, formas de acceso y pérdida de la condición de Fiscal, los derechos y deberes de los Fiscales y el régimen disciplinario». En la cúspide del Ministerio Fiscal se encuentra la Fiscalía General del Estado. El artículo 34 del Estatuto Orgánico dispone que las categorías de la carrera fiscal son las siguientes:

1. Fiscales de Sala del Tribunal Supremo, equiparados a Magistrados del Alto Tribunal. El Teniente Fiscal del Tribunal Supremo tendrá la consideración de Presidente de Sala.

2. Fiscales, equiparados a Magistrados.

3. Abogados-Fiscales, equiparados a Jueces.

\subsection{Letrados de la Administración de Justicia}

Con la entrada en vigor, el 1 de octubre de 2015, de la Ley Orgánica 7/2015, de 21 de julio, por la que se modifica la Ley Orgánica 6/1985 de 1 de julio del Poder Judicial, la categoría de personal judicial llamada hasta ese momento "secretario judicial» cambia su nombre al de «letrado de la administración de justicia». Según palabras de Mayor Gómez (2016):

[...] como antecedente legislativo se pone en conexión el precepto objeto de análisis con el modelo de oficina judicial que fue diseñado

Hikma 17 (2018),33 - 54 
por la Ley Orgánica 19/2003, de 23 de diciembre, de modificación de la Ley Orgánica 6/1985, de 1 de julio, del Poder Judicial, que desarrolló la Ley 13/2009, de 3 de noviembre, de reforma de la legislación procesal para la implantación de la nueva oficina judicial, en donde reforzar la figura de los Letrados de la Administración de Justicia era una de las prioridades de la reforma legal, atribuyéndose a éstos también otras funciones adicionales en materias colaterales a la función jurisdiccional, y en concreto se les reconoció la facultad de dictar determinadas resoluciones motivadas, denominadas decretos, relevantes para el desarrollo del proceso judicial.

El diario digital judicial confilegal recoge las palabras de un comunicado de Roig Valdivieso, delegado para Galicia del Colegio Nacional de Secretarios Judiciales: «Ahora la nueva LOPJ, resalta, aún más, las funciones propias de los Letrados de la Administración de Justicia» y dispone, en consonancia con el artículo 440 de la LOPJ, que son funcionarios públicos que constituyen un cuerpo superior jurídico, único, de carácter nacional, al servicio de la Administración de Justicia, dependiente del Ministerio de Justicia, y que ejercen sus funciones con el carácter de autoridad, ostentando la dirección de la Oficina judicial.

Cabe destacar la definición que recoge el llustre Colegio Nacional de Letrados de la Administración de Justicia: «Los Letrados de la Administración de Justicia, como depositarios de la Fe Pública Judicial en los Juzgados y Tribunales, constituyen una garantía para los derechos de los ciudadanos».

Por otro lado, la página legal informativojuridico.com ${ }^{2}$ expone que además de esta nueva denominación, contarán con nuevas competencias y funciones en el proceso civil. Con objeto de impulsar el proceso en los términos que establecen las leyes procesales dictará las resoluciones necesarias para la tramitación del proceso, salvo aquellas que las leyes procesales reserven a jueces o tribunales. Estas resoluciones se denominarán «diligencias», que podrán ser de ordenación, de constancia, de comunicación o de ejecución. Se llamará «decreto" a la resolución que dicte el Letrado de la Administración de Justicia con el fin de admitir la demanda, poner término al procedimiento del que tenga atribuida exclusiva competencia, o cuando sea preciso o conveniente razonar su decisión. Será siempre motivado y contendrá, en párrafos separados y numerados, los antecedentes de hecho y los fundamentos de derecho en que se basa.

\footnotetext{
${ }^{2}$ Información disponible en: https://bit.ly/2BbbnPz [Fecha de consulta: 27 de mayo de 2018].
}

Hikma 17 (2018), 33 - 54 


\subsection{Funcionarios al servicio de la Administración de Justicia}

Los funcionarios al servicio de la Administración de Justicia constituyen el personal encargado de dar soporte y apoyo en su labor a Jueces y Magistrados, Fiscales y Letrados de la Administración de Justicia. A tal efecto, desarrollan su labor en las Oficinas Judiciales y Fiscalías. La Ley Orgánica 19/2003, de 23 de diciembre, de modificación de la LOPJ, supone una profunda transformación en la organización de la Administración de Justicia y en la del personal a su servicio. El artículo 475 de la LOPJ clasifica a los Cuerpos de Funcionarios en Generales y Especiales. Son Generales "cuando su cometido consista esencialmente en tareas de contenido procesal, sin perjuicio de la realización de funciones administrativas vinculadas a las anteriores" y se refiere como tales a:

1. El Cuerpo de Gestión Procesal y Administrativa (antiguos oficiales). La titulación exigida para el acceso a este Cuerpo es la de Diplomado Universitario, Ingeniero Técnico, Arquitecto Técnico o equivalente.

2. El Cuerpo de Tramitación Procesal y Administrativa (antiguos auxiliares). Para el acceso a este Cuerpo se exigirá estar en posesión del título de Bachiller o equivalente.

3. El Cuerpo de Auxilio Judicial (antiguos agentes judiciales). Para cuyo ingreso se exigirá estar en posesión del título de graduado en ESO o equivalente.

Respecto a estas tres categorías de funcionarios y en relación con lo que exponíamos en el apartado anterior, correspondiente a huissier, sobre las traducciones que ya se habían aportado para este término francés, podemos afirmar que es el concepto que más difiere en los ordenamientos jurídicos de Francia y España. La formación no es en absoluto la misma, la categoría difiere igualmente, en Francia son oficiales ministeriales independientes y en España son funcionarios públicos. No es posible dar una equivalencia de ese término francés. Es el único concepto para el que propondremos mantener el término extranjero. Hemos consultado la página de la red judicial europea y la función que cumple en España ese profesional, tiene más relación con la que cumple el antiguo secretario judicial, el cual puede delegar en un funcionario que sí correspondería a alguna de las tres categorías mencionadas.

\subsection{Profesiones liberales al servicio de la Administración de Justicia}

Fuera de la categoría de funcionarios, pero también al servicio de la Administración de justicia, se encuentran los abogados y los procuradores, que son personas técnicas en derecho que defienden a las partes y la 
principal diferencia entre ambos radica en la función que tienen atribuida en el proceso. La función genérica del abogado consiste en ejercer profesionalmente la dirección y defensa de las partes o, en su caso, el asesoramiento jurídico, no solo en el proceso, sino también extrajudicialmente (González Montes, 1993: 215). Una categoría particular de abogados la constituyen los abogados del Estado, quienes ejercen la abogacía en defensa de los intereses de todos los organismos públicos (Hacienda, Seguridad Social, etc.).

En cuanto a los procuradores, su función consiste en la representación técnica de las partes en todos los procesos. A diferencia del abogado, que se ocupa de la defensa, el procurador es un órgano de representación de las partes en el proceso con exclusividad. A diferencia de Francia, en España las categorías de abogado y procurador como profesionales independientes no figuran en la clasificación que el Ministerio hace dentro de personal al servicio de la justicia.

En España, dado que hay competencias transferidas desde el Ministerio de Justicia a las Consejerías de las distintas Comunidades Autónomas y no en todos los casos son las mismas, intentar dar una clasificación unificada del personal resulta prácticamente imposible. El conocimiento de estos cambios de denominación en los distintos cargos de este grupo de funcionarios y de los anteriores, es importante para la labor del traductor.

\section{TÉCNICAS DE TRADUCCIÓN DE REFERENTES CULTURALES JUDICIALES}

Insistimos de nuevo en la dificultad que supone plantear soluciones de equivalencia a referentes culturales dentro del ámbito jurídico puesto que, como ya se ha indicado, los ordenamientos de cada país difieren en su funcionamiento. Tal y como expone Soriano Barabino en la actualidad,

la práctica de la traducción jurídica se debate entre los defensores de la equivalencia funcional y los que abogan por un enfoque más literal para la traducción de aquellas realidades para las que no es posible encontrar dicho equivalente (2016: 175).

La equivalencia funcional está directamente relacionada con el Derecho comparado. No podemos proponer una traducción de un referente origen si no conocemos tanto el funcionamiento de dicho referente en la lengua de partida como el funcionamiento de la propuesta que hacemos en la lengua de llegada. Por otro lado, las soluciones de traducción dependen del contexto de cada documento, especialmente del destinatario y de la 
finalidad del texto, por lo que somos conscientes de que no caben soluciones únicas; aportamos nuestro punto de vista desde la experiencia profesional y los problemas encontrados. Podemos afirmar que la traducción de este tipo de referente cultural necesita una serie de técnicas diferentes en función de los términos y en pocos casos vamos a poder aportar equivalentes funcionales. No obstante, las traducciones e interpretaciones jurídicas, juradas y judiciales entre francés y español pueden presentar un número muy amplio y variado de contextos y finalidades, por lo que las soluciones de traducción variarán en función de los casos. Unas veces el traductor tomará su decisión respecto al contexto de partida o llegada del texto, y otras veces será el cliente quien imponga algunas normas para la traducción.

Dentro del concepto de equivalencia vamos a incidir específicamente en la técnica de la equivalencia de referentes culturales en traducción jurídica y judicial. Concretamente en este ámbito, Holl (2012) analiza de forma cronológica las distintas teorías de seis investigadores en el ámbito de la equivalencia de referentes culturales en traducción jurídica: De Groot (1991), Weston (1991), Šarčević (1997), Harvey (2000), Mayoral (2002) y Martín Ruano (2005). De esas distintas teorías, resultan interesantes la de Šarčević, que propone tres tipos de equivalencia: casi-equivalencia, equivalencia parcial y no equivalencia, y la de Harvey que, partiendo de las cinco técnicas sugeridas por Weston, propone cuatro técnicas:

1. Equivalencia funcional (functional equivalence)

2. Equivalencia formal (formal equivalence)

\section{Transcripción o préstamo (transcription or borrowing)}

4. Traducción descriptiva (descriptive or self-explanatory translation)

Por su parte, tal y como expone Holl, Mayoral (2002) y Martín Ruano (2005) proponen lo que denominan «técnicas mixtas» y resumen el análisis efectuado de las teorías de los otros autores, enunciando que:

[...] aunque todos los estudiosos destacan que, a la hora de elegir entre varias opciones traductoras, desempeñan un papel importante la clase de texto, el receptor y la finalidad de la traducción, De Groot (1991, 1999) Weston (1991) y Šarčević (1997) dan una clara preferencia a los equivalentes funcionales, es decir, a la búsqueda de un término que desempeñe en el ordenamiento jurídico de llegada la misma función o una función parecida a la que corresponde al término original en el sistema legal de partida (Holl, 2012: 14).

Hikma 17 (2018),33 - 54 
Por otro lado, Orozco Jutorán realiza dos grandes clasificaciones de técnicas: equivalentes conceptuales y lingüísticos. Dentro de los primeros divide a su vez en cuatro, las posibles equivalencias: total, natural, funcional y contextual y los equivalentes lingüísticos, los subdivide en cinco: traducción acuñada, traducción léxica o calco, préstamo, traducción perifrástica y neologismo (2014: 246-259).

Puede observarse que existen diferentes enfoques a la hora de hacer una taxonomía de técnicas de traducción, pero a pesar de tener distintas denominaciones algunas de las técnicas presentan coincidencias en cuanto al fenómeno al que se refieren (préstamo, equivalencia funcional traducción perifrástica o explicativa...). Consideramos asimismo que puede haber ciertos distanciamientos entre las técnicas que los distintos autores podamos aportar teniendo en cuenta la especialidad y las lenguas que se estén investigando.

En el momento de aportar una solución para la traducción de referentes culturales en traducción jurídica y judicial, como son, en nuestro caso, las denominaciones del personal, se plantean varias técnicas posibles. La elección de una u otra técnica, como ya se ha dicho, dependerá de la finalidad de la traducción y la comprensión de esa traducción por parte del destinatario en la lengua meta. Por esta razón, en la tabla que presentamos más abajo proponemos en el caso de algunos jueces franceses, tanto la traducción literal de juez como la de juzgado, más funcional.

A partir del análisis pragmático-funcional que hemos realizado, identificamos cinco técnicas de traducción:

1. Equivalencia funcional: existe un término meta que coincide con la realidad jurídica del término de partida. Aquí presentamos algunos de los ejemplos terminológicos:

- avocat-abogado,

- greffier-letrado de la Administración de Justicia,

- procureur-fiscal.

Dentro de esta técnica, hay dos casos en los que existe una doble opción de traducción en español; para utilizar el término correcto debemos tener conocimiento del contexto del documento original. Son los casos de juge y magistrat.

2. Traducción literal:

- juge de l'exécution-juez de ejecución,

- juge d'instance-juez de instancia,

Hikma 17 (2018), 33 - 54 
- juge des libertés et de la détention-juez encargado de las libertades y la detención.

En estos casos consideramos oportuna la literalidad, aunque dependería de la función del texto. No obstante, en nuestra opinión, el término francés analizado corresponde a un referente jurídico del ordenamiento de ese país, por lo que no existe una equivalencia exacta ni real de esa función, a pesar de que sí se puede explicar utilizando una técnica de traducción literal con objeto de informar al destinatario.

\section{Préstamo:}

El único caso sería el del término huissier. Hemos demostrado en los apartados anteriores que los términos que habitualmente se han utilizado para traducir en español este concepto francés, no corresponden con la realidad del profesional que realiza la misma labor en España. Tiene rasgos comunes con distintas funciones de personal judicial, por lo que consideramos que debemos utilizar el préstamo francés y en función de la finalidad y del destinatario de la traducción, aportar una nota explicativa con las principales características de este profesional francés.

4. Técnica mixta en la que se van a utilizar a la vez dos de las anteriores: avocat auprès du Conseil d'État et de la Cour de cassation-abogado del Conseil d'État/de la Cour de cassation.

5. Técnica explicativa en la que aportamos una traducción menos funcional y más aclaratoria en la denominación para que sea comprensible por parte del destinatario: juge de la mise en état-juez de instrucción civil. En este caso, el término francés hace referencia a una realidad francesa que no existe en España y que tampoco puede traducirse de forma literal porque no significaría nada en español, por lo que una traducción explicativa permite informar al destinatario conocedor del Derecho, acerca de la competencia de ese juez, a pesar de que el resultado en español pueda resultar incluso contradictorio.

Después de la presentación de los apartados 2 y 3 que forman parte del conocimiento temático en traducción de este tipo de referentes culturales judiciales y de haber expuesto las técnicas de traducción que se pueden aplicar en este caso, exponemos el glosario bilingüe resultante de los términos relativos al personal judicial:

\begin{tabular}{|c|l|l|}
\hline Término francés & Propuesta en español & Técnica \\
\hline Avocat & Abogado & Equivalencia funcional \\
\hline
\end{tabular}




\begin{tabular}{|c|c|c|}
\hline $\begin{array}{l}\text { Avocat auprès du Conseil } \\
\text { d'État et de la Cour de } \\
\text { cassation }\end{array}$ & $\begin{array}{l}\text { Abogado del Conseil de l'État } \\
\text { y la Cour de cassation }\end{array}$ & Técnica mixta \\
\hline Avocat général & Fiscal & Equivalencia funcional \\
\hline Avoué & Procurador & Equivalencia funcional \\
\hline Greffier & $\begin{array}{l}\text { Letrado de la Administración } \\
\text { de Justicia }\end{array}$ & Equivalencia funcional \\
\hline Huissier & Huissier & Préstamo \\
\hline Juge & Juez/Magistrado & Equivalencia funcional \\
\hline Juge aux affaires familiales & $\begin{array}{l}\text { Juez de } \quad \text { asuntos } \\
\text { familiares/Juez de familia }\end{array}$ & $\begin{array}{l}\text { Traducción } \\
\text { literal/Equivalencia } \\
\text { funcional }\end{array}$ \\
\hline $\begin{array}{l}\text { Juge de l'application des } \\
\text { peines }\end{array}$ & $\begin{array}{l}\text { Juez/Juzgado de vigilancia } \\
\text { penitenciaria }\end{array}$ & Equivalencia funcional \\
\hline Juge des enfants & Juez de menores & Traducción literal \\
\hline Juge de l'exécution & Juez de ejecución & Traducción literal \\
\hline Juge d'instance & Juez de instancia & Traducción literal \\
\hline Juge d'instruction & Juez de instrucción & Traducción literal \\
\hline $\begin{array}{l}\text { Juge des libertés et de la } \\
\text { détention }\end{array}$ & $\begin{array}{l}\text { Juez encargado de las } \\
\text { libertades y la detención }\end{array}$ & Traducción literal \\
\hline Juge de la mise en état & Juez de instrucción civil & Técnica explicativa \\
\hline Juge des tutelles & Juez de tutela & Traducción literal \\
\hline Magistrat & Magistrado/Fiscal & Equivalencia funcional \\
\hline Procureur & Fiscal & Equivalencia funcional \\
\hline
\end{tabular}

Tabla 2: Listado terminológico del personal y propuesta de traducción Fuente: elaboración propia

\section{CONCLUSIONES}

En los apartados anteriores, en los que presentamos las funciones del personal de justicia, tanto en Francia como en España, podemos concluir que, en siete casos, tienen una equivalencia funcional en español, en siete casos se pueden traducir de forma literal, pues su sentido se entiende perfectamente en español sin provocar falsos sentidos ni ambigüedad y otras funciones van a necesitar otras técnicas presentadas: préstamo, técnica mixta o explicativa.

Hikma 17 (2018), 33 - 54 
Resulta patente la necesidad de la competencia temática en la traducción e interpretación judicial y jurídica en general sin la cual, la comprensión en la lengua meta podría presentar ambigüedades, impropiedades e incluso falsos sentidos. Queda, además, demostrado que el término origen no siempre hace referencia a una figura jurídica del ordenamiento jurídico de destino, por lo que tenemos que acudir a estrategias para la comprensión en la lengua meta.

Esa necesidad, ya citada, supone profundizar en el análisis de los ordenamientos jurídicos origen y meta, lo que nos lleva a continuar con futuras investigaciones dentro del ámbito judicial. La terminología analizada en nuestra investigación, posteriormente, será objeto de informatización dentro del proyecto de innovación docente 2018/2019 titulado "UCOTerm" Sitio web para la difusión de recursos para la traducción jurídico - judicial francés - español", recurso en línea de acceso gratuito.

\section{REFERENCIAS BIBLIOGRÁFICAS}

Administración de Justicia. Gobierno de España. Recuperado de https://bit.ly/2Q78TKs

Campos Plaza, N. (2010). Equivalents terminologiques des organes judiciaires et de l'ordre juridictionnel français et espagnol. Anales de Filología Francesa, 18, 71-84.

Code de procédure pénale francés. Versión consolidada a 1 de junio de 2017. Recuperado de https://bit.ly/2PZRGIR

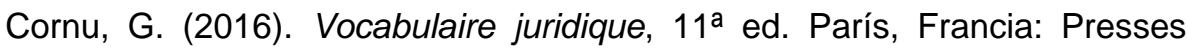
Universitaires de France.

Delgado Pugés, I. (2010). La composición del Ministerio Fiscal en España y en Francia: cuestiones de traducción y terminología. Anales de Filología Francesa, 18, 119-135.

Fernández Martínez, J. M. (coord.) (2012). Diccionario Jurídico, 6ª ed. Cizur Menor (Navarra): Thomson Reuters-Aranzadi.

González Montes, J. L. (1993). Instituciones de Derecho Procesal. Tomo I: La jurisdicción y sus órganos. $3^{\text {an }}$ ed. Madrid, España: Tecnos.

${ }^{3}$ Plataforma de la Universidad de Córdoba accesible en www.uco.es/ucoterm. 
Holl, I. (2012). Técnicas para la traducción jurídica: revisión de diferentes propuestas, últimas tendencias, Hermeneus. Revista de Traducción e Interpretación, 14, 191-216.

Ley Orgánica 6/1985, de 1 de julio, del Poder Judicial. Última actualización publicada el 28/10/2015. Boletín Oficial del Estado, 2 de julio de 1985 (157), 20632-20678. Recuperado de https://bit.ly/1cBJyQw

Mayor Gómez, R. (2016). Comentarios a la sentencia del tribunal constitucional de 17 de marzo de 2016: inconstitucionalidad y nulidad del artículo 102 bis, primer párrafo del apartado 2, de la ley 29/1998, de 13 de julio, reguladora de la jurisdicción contencioso-administrativa. Gabilex: Revista del Gabinete Jurídico de Castilla-La Mancha, 5, 239247.

Ministerio de Justicia francés. Recuperado de https://bit.ly/2B9Lf7t/

Ministerio de Justicia español. Recuperado de https://bit.ly/2Do6vrU

Mallandrich Miret (2013). Recuperado de https://bit.ly/2QNxz7A

Orozco Jutorán, M. (2014). Propuesta de un catálogo de técnicas de traducción: la toma de decisiones informada ante la elección de equivalentes, Hermeneus, 16, 233-264.

Peñaranda López, A. (2015). Proceso Penal Comparado (España, Francia, Inglaterra, Estados Unidos, Rusia) Descripción y terminología. 2a edición. Colección Interlingua. Granada, España: Comares.

- (2011). El proceso penal en España, Francia, Inglaterra y Estados Unidos: descripción y terminología. Colección Interlingua. Granada, España: Comares.

Soriano Barabino, G. (2016). La traducción de los órganos jurisdiccionales franceses en tanto que instituciones culturales, Revista de Llengua i Dret, Journal of Language and Law, 66, 172-188.

- (2013). La competencia temática en la formación de traductores de textos jurídicos en la combinación lingüística francés/español, Estudios de Traducción, 3, 45-56. 